Universidad

BIBLIOTECA

Document downloaded from the institutional repository of the University of Alcala: http://dspace.uah.es/dspace/

This is a postprint version of the following published document:

García-Valdés et al., 2015. Effects of climate, species interactions, and dispersal on decadal colonization and extinction rates of Iberian tree species. Ecological Modelling, vol. 309-310, pp.118-127.

Available at http://dx.doi.org/10.1016/i.ecolmodel.2015.04.003

(C) 2015 Elsevier

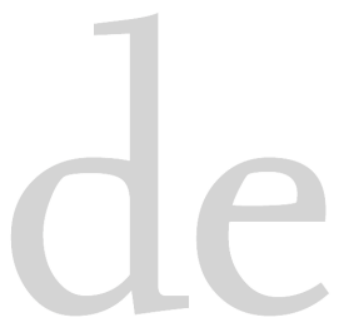

(Article begins on next page)

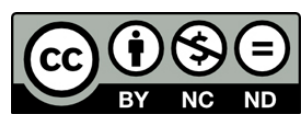

This work is licensed under a

Creative Commons Attribution-NonCommercial-NoDerivatives

4.0 International License. 


\section{Effects of climate, species interactions, and dispersal on decadal colonization and extinction rates of Iberian tree species}

Authors: Raúl García-Valdés ${ }^{\mathrm{a}, \mathrm{b}, \mathrm{c},},{ }^{*}$, Nicholas J. Gotellid, Miguel A. Zavala ${ }^{\mathrm{b}}$, Drew W. Purves ${ }^{\mathrm{e}}$ and Miguel B. Araújo a,f,g

\section{Author Affiliations:}

${ }^{a}$ Department of Biogeography and Global Change. National Museum of Natural Sciences, CSIC. C/ José Gutiérrez Abascal, 2, 28006, Madrid, Spain.

b Forest Ecology and Restoration Group, Department of Life Sciences, Science Building, University of Alcala, 28871, Alcalá de Henares (Madrid), Spain.

${ }^{c}$ CEFE UMR 5175, CNRS - Université de Montpellier - Université Paul-Valéry Montpellier EPHE, 1919 Route de Mende, F-34293 Montpellier Cedex 5, France.

${ }^{\mathrm{d}}$ Department of Biology, University of Vermont (Burlington). USA.

${ }^{\mathrm{e}}$ Computational Ecology and Environmental Science group, Microsoft Research Cambridge, 7 J J Thomson Ave, Cambridge CB3 OFB, UK.

${ }^{\text {f} ~ C I B I O-I n B I O, ~ U n i v e r s i d a d e ~ d e ~ E ́ v o r a, ~ C I B I O, ~ L a r g o ~ d o s ~ C o l e g i a i s, ~} 7000$ Évora, Portugal.

g Centre for Macroecology, Evolution and Climate. Department of Biology. University of Copenhagen. Copenhagen, DK-2100, Denmark.

* Corresponding author:

Raúl García-Valdés https://orcid.org/0000-0001-6399-4709

E-mails: $\underline{\text { raul.garcia.valdes @ gmail.com }}$ 


\begin{abstract}
We studied the relative importance of climate, abundance of potentially competing species, and dispersal in explaining local colonization and extinction rates of tree species throughout mainland Spain. We used a Bayesian framework to parameterize a patch occupancy model to 23 species censused in 46,596 permanent plots in a $1 \times 1$ grid across most Spanish forests. For most species, dispersal was the single best predictor of colonization, whereas climate and dispersal were equally important as predictors of extinction. Precipitation was positively correlated with the colonization rate of 12 out of 13 deciduous broad-leaved species, and negatively correlated with the extinction rate of 9 of them. In contrast, precipitation equally decreased colonization and extinction of 5 out of 8 of needle-leaved species (Juniperus and Pinus spp.). There was, however, marked variation among species in the magnitude of these effects, with some species exhibiting contrasting patterns for the colonization and the extinction process. Abundance of competing tree species (= summed plot basal area) was consistently correlated with decreased colonization of all needle-leaved species, and it increased the extinction rate of 6 out of 8 of these species. It had, nonetheless, weak facilitative effect on some broad-leaved species by promoting colonization (3 of 13 species) and decreasing extinction (7 of 13 species). With local colonization and extinction data, non-equilibrial and dynamic species distribution modelling can be improved by incorporating measures of biotic interactions and dispersal effects, along with traditional climate variables.
\end{abstract}

\title{
Key-words:
}

Competition, drivers of species distribution, non-equilibrium forest dynamic, regional extent, seed dispersal kernel, tree abundance.

\section{Introduction}


Species distribution models (SDMs) have been widely used in conservation planning and management, in forecasting the effects of invasive species and climate change, and in assessing the risk of disease transmission (Araújo and Peterson, 2012). SDMs, especially under scenarios of climate change, have traditionally been fit with climatic variables only (Pearson and Dawson, 2003), yet it is well known that non-climatic factors affect the distribution of species, especially at local scales (Davis et al., 1998; Hampe, 2004; Ibáñez et al., 2006; Iverson and Prasad, 1998; Pearson and Dawson, 2003). In particular, dispersal dynamics (Engler et al., 2009) and species interactions may be important but are not well-studied (Araújo and Luoto, 2007; Godsoe and Harmon, 2012; Kissling et al., 2012; Pulliam, 2000; Wisz et al., 2013), perhaps because it is challenging to incorporate these factors into realistic SDMs (Araújo and Rozenfeld, 2014).

One of the challenges is that, until recently, many analyses in biogeography and macroecology have been based on correlations between the static presence of individual species and potential predictor variables (Gotelli et al., 2009). Moreover, SDMs fit with static records of species occurrences implicitly assume that species distributions are in climatic equilibrium (Pearson and Dawson, 2003; Svenning and Sandel, 2013). Although such equilibria may exist for some species at particular spatial scales (Araújo and Pearson, 2005), many distributions are dynamic (Montoya et al., 2007; Peterson et al., 1999; Skov and Svenning, 2004; Woodward et al., 1990), such as those of poorly-dispersing taxa that might rarely achieve equilibrium with climate (Araújo and Pearson, 2005; see also Hof et al., 2012), or those of taxa that were strongly affected by human activities in the past (e.g. tree species in mainland Spain, García-Valdés et al., 2015; García-Valdés et al., 2013). Species distributions ultimately result from dynamic local colonizations and extinctions, and ideally, the individual contribution of dispersal, species interactions and climatic variables to 
colonization and extinction should be quantified. However, the temporally replicated data needed for such analyses are rare.

Here, we investigated the relative importance of variables measuring effects of climate, species interactions, and dispersal as predictors of local colonization and extinction of tree species in mainland Spain (Fig. 1). To do so, we used a climate-dependent patch occupancy model (developed by García-Valdés et al., 2013) to study plot-level colonization and extinction rates of tree species from two consecutive nation-wide forest inventories in Spain. Specifically, we quantified the relative importance, and direction of influence, of each of these three drivers, and tested for consistent differences between broad-leaved and needle-leaved species, and between wind- and animal-dispersed species.

These analyses can provide the foundation for a dynamic meta-community model that could be used to simulate forest tree species distributions under different climate and habitat change scenarios. The spatial scale of this study encompasses a large regional extent $(1000 \mathrm{~km})$, but a relatively small spatial grain $(25 \mathrm{~m}$ radius plots through a $1 \times 1 \mathrm{~km}$ grid). Dynamic census data collected at such scales allowed us to study how the processes of colonization and extinction, which ultimately lead to species distributions at regional scales, depend on local drivers.

\section{Material and Methods}

\subsection{Tree census data and abiotic variables}

We recorded decadal colonization of unoccupied plots and extinction of occupied plots between the second (1986-1996; Villaescusa and Diaz, 1998) and third (1997-2007; Villanueva, 2004) 
Spanish Forest Inventories. In both inventories, the same 46,596 permanent plots located in a $1 \times$ $1 \mathrm{~km}$ grid across most forests in mainland Spain were surveyed. Each plot was formed by four concentric sub-plots of different radii ranging from $5 \mathrm{~m}$ to $25 \mathrm{~m}$. The minimum size for trees censused in the smallest sub-plot was $7.5 \mathrm{~cm}$ of diameter at breast height. In each survey, the identities and sizes of trees were recorded. A total of 72 tree species was recorded across mainland Spain, with tree species richness per plot ranging from 1 to 9 (average $=1.51$ tree species/plot). We used 23 tree species, including 4 taxa that could be identified only to genus (Table A.1). We excluded species with fewer than 10 incidences in each census and with fewer than 5 colonizations or extinctions. We also excluded Pinus radiata and Populus nigra, because their distributions largely reflect planting, and Ulmus minor, because its distribution largely reflects mortality from Dutch elm disease. See García-Valdés et al. (2013) for more detail on data characteristics.

Climate predictors were obtained from a regional climate model, which itself was based on data from 5426 weather stations, and downscaled through ordinary co-kriging to match the forest inventory $1 \times 1 \mathrm{~km}$ grid (Gonzalo, 2008). To select only two relevant climatic variables, we explored co-linearity, using Principal Component Analyses (package 'stats'; R Core Team, 2014), among 14 climate variables that are recognized as physiologically important for trees (analyses not shown). We selected first the variable maximum temperature of the hottest month (TMMH) because it had the strongest correlation (0.337) with the first PCA axis (which explained 53.2\% of the variance). The second axis explained $25.5 \%$ of the variance, and the two variables most strongly correlated with it were winter precipitation $(P w ;-0.408)$ and the minimum temperature of the coldest month (TMMC; -0.426). Of these, we selected $P w$ because that way we had an energy- and a water-related variables, instead of two energy-related ones (see Hawkins et al., 2003). 
To quantify interspecific interactions, the presence, density, or basal area of the other 72 species in the database could theoretically be used as predictor variables, but this would add 72 potential predictor variables to the model. To keep the analysis simpler and to facilitate model calibration, we used the summed basal area of all individuals from other tree species in the plot (BA, in $\mathrm{mm}^{2}$ ) as a simple aggregate index of the potential strength of interactions with other species. Such interactions might reflect direct competition for shared resources such as space, light, water, and soil nutrients, as well as indirect effects that are mediated through other species of pollinators, herbivores, seed predators, and dispersers. Statistical associations between BA and each studied species might reflect competitive effects (if greater BA in a plot produces a decrease in colonizations and/or an increase in extinctions), or a facilitative effect (if greater BA produces an increase in colonizations and/or a decrease in extinctions). This latter effect could be particularly important in the drought-prone southern regions of Spain (Pugnaire et al., 1996).

For each census plot and species, we represented the effects of dispersal as a metric calculated with a logistic-shaped dispersal kernel function (see Eqns 3-6). We fit this function with the distance from the survey plot to all other plots occupied by the same species, within a $50 \mathrm{~km}$ radius, to simulate random dispersal. To simulate directed dispersal, we weighed this function by the distance to all the suitable (= forested) plots.

We explored correlation between the variables of all studied drivers (package 'stats'; R Core Team, 2014), but found no strong association among them (Appendix 1). Finally, to test whether the results were influenced by recent silvicultural activities, we repeated the analysis excluding 13,000 
plots that, in the last inventory, showed signs of human intervention such as logging, tilling, or other major land-use changes. We found no important changes in the results when these managed plots were excluded (analyses not shown).

\subsection{Model structure}

The model is described by the following set of functions, in which the probability of species $j$ being present $\left.\left[X_{j, q}(t+1)=1\right)\right]$ or absent $\left[X_{j, q}(t+1)=0\right]$ within plot $q$ at time $t+1$ is:

$$
P\left[X_{j, q}(t+1) \mid X_{j, q}(t)\right]= \begin{cases}C_{j, q}(t) & \text { if } X_{j, q}(t)=0 \text { and } X_{j, q}(t+1)=1 \\ 1-C_{j, q}(t) & \text { if } X_{j, q}(t)=0 \text { and } X_{j, q}(t+1)=0 \\ E_{j, q}(t) & \text { if } X_{j, q}(t)=1 \text { and } X_{j, q}(t+1)=0 \\ 1-E_{j, q}(t) & \text { if } X_{j, q}(t)=1 \text { and } X_{j, q}(t+1)=1\end{cases}
$$

where $C_{j, q}(t)$ is the probability of local colonization and $E_{j, q}(t)$ is the probability of local extinction, for species $j$ in plot $q$ between $t$ and $t+1$.

\section{$\underline{\text { Colonization rate }}$}

The probability of colonization of plot $q$ by a species $j$ (Eqn. 2) was determined by the dispersal into the plot (Eqns 3-6), and by the probability of seeding establishment and growth to the point of detection in the next inventory (Eqns 7-9).

$C_{j, q}(t)=S_{j, q}^{\lambda} \alpha_{j, q}$

where $S_{j, q}$ is the dispersal of the species $j$ in the plot $q, \lambda$ is a parameter and $\alpha_{j, q}$ is a coefficient 
representing the probability that each incoming seed establishes and grows.

Dispersal could be random with respect to the surrounding habitat (Eqns 3 and 4), in which seeds leaving a donor plot $q^{\prime}$ were scattered randomly, including to unsuitable habitat plots (e.g. crops), or it could be directed with respect to habitat (Eqns 5 and 6), in which seeds landed only within suitable (forested) habitat.

\section{Random Dispersal}

$S_{j, q}(t)=\left(\frac{1}{\Psi_{q}}\right) \sum_{H(q)}\left\{X_{j, q^{\prime}}(t) \exp \left[-\left(\frac{d_{q, q^{\prime}}}{\sigma}\right)^{2}\right]\right\}$

where

$\Psi_{q}=\sum_{H^{\prime}(q)}\left\{\exp \left[-\left(\frac{d_{q, q^{\prime}}}{\sigma}\right)^{2}\right]\right\}$

Directed Dispersal

$S_{j, q}(t)=\left(\frac{1}{\Omega_{q}}\right) \sum_{H(q)}\left\{X_{j, q^{\prime}}(t) \exp \left[-\left(\frac{d_{q, q^{\prime}}}{\sigma}\right)^{2}\right]\right\}$

where

$\Omega_{q}=\sum_{H(q)}\left\{X_{q^{\prime}}(t) \exp \left[-\left(\frac{d_{q, q^{\prime}}}{\sigma}\right)^{2}\right]\right\}$

where $d_{q, q^{\prime}}$ is the Euclidean distance between the receiving plot $q$ and the donor plot $q^{\prime}$. The set $H^{\prime}$ (q) contains all neighbour plots in the neighbourhood of $q$ (defined as within $50 \mathrm{~km}$ ). The set 
$H$ (q) contains only those neighbour plots that are suitable.

With random dispersal, as the number of suitable plots decreases in a region, so too does the dispersal into every plot, as a greater fraction of the total seed output is lost to unsuitable plots. By contrast, in directed dispersal, the seed output from each plot $q^{\prime}$, is divided by $\Omega_{q}$, representing the density of suitable plots around $q$, weighted by the dispersal function. The effect is that, under directed dispersal, as the number of suitable plots decreases in a region, the dispersal into each plot increases because seeds are never lost to unsuitable plots.

The probability of a seed establishing and growing, $\alpha_{j, q}$, depends on the environmental and biotic variables in the plot:

$\alpha_{\mathrm{j}, \mathrm{q}}=\frac{1}{1+\mathrm{e}^{-\mathrm{fc}_{\mathrm{j}, \mathrm{q}}}}$

where $f c_{j, q}$ can be one of the two following functions:

$f c_{j, q}=\gamma_{0}+\gamma_{1} P_{j, q}+\gamma_{3} T_{j, q}+\gamma_{5} B A_{j, q}$

$f c_{j, q}=\gamma_{0}+\gamma_{1}\left(P_{j, q}-\gamma_{2}\right)^{2}+\gamma_{3}\left(T_{j, q}-\gamma_{4}\right)^{2}+\gamma_{5}\left(B A_{j, q}-\gamma_{6}\right)^{2}$

where $\gamma_{i}$ are parameters estimated from the inventory data, $P$ is the precipitation variable, $T$ is the temperature variable, and $B A$ is the biotic interaction variable.

\section{$\underline{\text { Extinction rate }}$}


The probability of extinction (Eqn. 13) was calculated as the probability that all individuals of the species die in the plot (Eqns 14-16), and the probability that colonization from neighbouring plots does not rescue the species from extinction in the plot (Eqns 4-7) (Brown and Kodric-Brown, 1977).

$E_{j, q}(t)=\delta_{j, q}\left(1-S_{j, q}\right)^{\lambda}$

where $\delta_{j, q}$ is the probability of the species $j$ going extinct in the plot $q, S_{j, q}$ is the probability of rescue effect, and $\lambda$ is a scaling parameter.

$\delta_{j, q}(t)=\frac{1}{1+e^{-f e_{j, q}}}$

where $f e_{j, q}$ can be one of the two following functions:

$$
\begin{aligned}
& f e_{j, q}=\beta_{0}+\beta_{1} P_{q}+\beta_{3} T_{q}+\beta_{5} B A_{q} \\
& f e_{j, q}=\beta_{0}+\beta_{1}\left(P_{q}-\beta_{2}\right)^{2}+\beta_{3}\left(T_{q}-\beta_{4}\right)^{2}+\beta_{5}\left(B A_{q}-\beta_{6}\right)^{2}
\end{aligned}
$$

where $\beta_{i}$ are parameters estimated from the inventory data, $P$ is the precipitation variable, $T$ is the temperature variable, and $B A$ is the biotic interaction variable.

\subsection{Model parameterization}

For each combination of model and species, we estimated model parameters using Metropolis Hastings Markov Chain Monte Carlo sampling (see Table A.2.). We used flat (= uninformative) 
prior distributions, so the results of the analysis depend only on the likelihood. The likelihood was the probability of observing a colonization or extinction in the inventory data, given a species, model and set of parameters $\theta$. We did not impose a hierarchical structure for the species parameters, so the model selection and parameter estimates for each species were extracted purely from the data.

Consider the inventory observations for species $j$, and plot $q$, taken at times $t$ and $t+\Delta t$. For both $t$ and $t+\Delta t$, the data record whether species $j$ was present, or absent, in plot $q$. Call these measures $X_{j, q}^{o b s}(t)$ and $X_{j, q}^{o b s}(t+\Delta t)$ respectively. Then, via Eqns 14, any particular $\theta$ implies a probability for $X_{j, q}^{o b s}(t)$ and $X_{j, q}^{o b s}(t+\Delta t)$, so long as we are careful to take into account the number of years between the surveys, $\Delta t$ :

$$
P\left[X_{j, q}^{o b s}(t+\Delta t) \mid X_{j, q}^{o b s}(t), \theta\right]= \begin{cases}1-\left[1-E_{j, q}(t)\right]^{\Delta t} & \text { if } X_{j, q}^{o b s}(t)=1 \text { and } X_{j, q}^{o b s}(t+\Delta t)=0 \\ {\left[1-E_{j, q}(t)\right]^{\Delta t}} & \text { if } X_{j, q}^{o b s}(t)=1 \text { and } X_{j, q}^{o b s}(t+\Delta t)=1 \\ 1-\left[1-C_{j, q}(t)\right]^{\Delta t} & \text { if } X_{j, q}^{o b s}(t)=0 \text { and } X_{j, q}^{o b s}(t+\Delta t)=1 \\ {\left[1-C_{j, q}(t)\right]^{\Delta t}} & \text { if } X_{j, q}^{o b s}(t)=0 \text { and } X_{j, q}^{o b s}(t+\Delta t)=0\end{cases}
$$

where the $E_{j, q}(t)$ and $C_{j, q}(t)$ values are those associated with the parameter combination represented by $\theta$. To calculate the probability of the whole of the inventory data for species $j$ we can assume independence between observations, which makes the combined probability a product over the probabilities associated with each plot, over all plots. Because we work with the loglikelihood $\ell\left(X^{o b s} \mid \theta\right)$, this product becomes a sum of the log of those probabilities. 
$\ell\left(X^{o b s} \mid \theta\right)=\sum_{q} \ln \left\{P\left(X_{j, q}^{o b s}(t+\Delta t) \mid X_{j, q}^{o b s}(t), \theta\right)\right\}$

With the log-likelihood defined, we used the sampling method Metropolis-Hastings MCMC algorithm, and 50000 iterations after a burn-in period, to generate, for each combination of model and species: parameter estimates (including 95\% credible intervals), and Akaike Information Criterion (AIC) values, which were used to judge the relative support for the different models (see below). We opted to use MCMC sampling rather than some alternative parameter search algorithm (such as simulated annealing) because we wished to estimate the uncertainty of the parameters. The two broad classes of approaches to implement in this case are posterior samples from MCMC vs. the maximum likelihood profile method from the results of some other form of parameter search algorithm. The MCMC is simpler to implement and converges on the correct intervals with many fewer samples (not discussed further here). With non-informative priors, the posterior is simply proportional to the likelihood. Therefore, with substantial amounts of data (as we had here) we expect both the posterior credible intervals, and the confidence intervals from the profile method, if correctly applied, to be very similar. The familiar AIC approach for model comparison should also yield very similar results to Bayesian methods such as the DIC or Reversible Jump MCMC (Green, 1995).

The MCMC algorithm that we used was 'Filzbach', which has been used in a wide variety of ecological analyses, extensively tested in scenarios using pseudo data (now shown here), and is available, with examples, at http://research.microsoft.com/enus/um/cambridge/groups/science/tools/filzbach/filzbach.htm. Filzbach runs four different phases of iterations, to (1) converge on the posterior distribution and adjust the details of the proposal 
distributions to be optimal for sampling from the posterior; (2) record samples from the posterior (these can be used to generate posterior means and credible intervals); (3) seeks the maximum likelihood and maximum likelihood estimates (MLE) from a non Metropolis-Hastings phase which in turn allows the calculation of AIC and BIC values, which; (4) applies the profile method to calculate confidence intervals around the MLE estimates from a non Metropolis-Hastings phase. We used the maximum likelihood returned from phase 3 to calculate AIC values. We used the intervals returned from phase 2 , rather than phase 4 , as our estimate of parameter uncertainty because, as noted before, we consider intervals from posterior sampling to be more robust than those from the profile method. For more information on model structure and parameterization see García-Valdés et al. (2013) and Purves et al. (2007).

\subsection{Combination of different drivers}

Models of colonization and extinction rate were fit for each factorial combination of the three types of predictor variables (referred to as drivers in this study: climate, interactions, and dispersal), ranging from a null model in which none of the three driver variables was included (-,-,-), to the 'saturated model' which included all three sets of driver $(+,+,+)$. Thus, a suite of 8 different kinds of models were fit for each species, depending on which combination of the 3 drivers was included in the model. Moreover, for each type of driver, we tested two different functional forms to describe the relationship with the driver. For the climatic and interactions variables, we fit monotonic, or unimodal curves (Eqns 8 vs 9 for colonization; 12 vs 13 for extinctions). For the dispersal effect, we fit logistic kernel functions that could be random or directed with respect to forested habitat in surrounding plots (eqns 3-4, vs eqns 5-6). For each of the 23 species, these parameter combinations yielded 45 different models for colonization, and 45 models for extinction. 


\subsection{Relative importance of climate, interactions and dispersal}

To assess the relative importance of climate, species interactions, and dispersal in determining colonization and extinction rates, we assessed the support for each alternative combination of drivers to be the best at predicting each process. Because we needed to compare results for different species, which had different amounts of data, we did not use AIC values, but Akaike weights. Akaike weights range from 0 to 1 , so they can be compared and averaged across different datasets. The Akaike weight $\left(w_{i}\right)$ aims to calculate the probability that a specific model, from a set of models, will provide the best predictions (Burnham and Anderson, 2002). The average $w_{i}$ of all models containing a particular driver (or set of drivers) can then be summed to assess the relative predictive power of that variable. This approach requires that all drivers must be included in a similar number of models. In our case, however, some of the drivers were represented by more models than others. To circumvent this problem, we selected only the single best-fitting model (i.e. the one with the lowest AIC) for each driver combination, and estimated its $w_{i}$ in comparison with the best-fitting models of the other driver combinations. The $w_{i}$ of each combination of drivers, represented an estimate of the probability that this combination best described the studied process (colonization or extinction) for a given species (see Table A.3.).

To estimate the relative importance of the different drivers, we first compared the three drivers individually (i.e., climate, interactions and dispersal), calculating $w_{i}$ for each as described above. We then compared all possible combinations of drivers. To summarize our results and draw general conclusions regarding the relative importance of the studied factors, we created boxplots of the distribution of $w_{i}$ values for each driver combination, taken over the different species. We initially 
analysed all 23 species together, and then split the species into two functional groups: needleleaved $(\mathrm{N}=8)$ and deciduous broad-leaved $(\mathrm{N}=13)$ species (see Table A.1). There were also 2 evergreen broad-leaved species, which were included in the general analysis but were not analysed separately as a functional group. We also partitioned the species into those that were winddispersed $(\mathrm{N}=10)$ and those that were animal-dispersed $(\mathrm{N}=13$; see Table A.1).

\subsection{Magnitude and direction of effects}

The model selection approach above aimed to identify which drivers had the greatest predictive power for a given process or species. But such a comparison does not indicate the direction or relative magnitude of effects (e.g. temperature could have high predictive power by increasing, or decreasing, colonization and with greater or lesser magnitude for a particular species). To assess the direction and magnitude of the effects, we studied the parameters associated with each driver's variable. For this analysis we used only the saturated models. In this way, we statistically removed the effect of the other drivers before analysing the variable/s of each one. To study the parameters associated with climate and biotic interactions, we used the monotonic functional form associated with each variable so that each variable was constrained by only one parameter. This allowed us to explore the magnitude, as well as the direction (sign) of the effect of a particular driver, and to

compare this among species. The parameters associated with dispersal were always positive because of the functional form that we used to fit the species dispersal kernel (see above and Table A.2,), which is based on the idea that dispersal is always positively associated with colonization and negatively associated with extinction. Therefore, we only studied the magnitude (and not the sign) of the effect of dispersal in each species. Larger dispersal parameters implied that the species dispersed more from longer distances compared to a species with small dispersal parameters. 
However, our estimations of these dispersal kernels were based purely on the distance to other plots that were occupied by the species, thus, dispersal was inferred from the spatial configuration of species occurrences in the area surrounding each potentially colonizable plot, and not from the number or characteristics of the seeds produced by each species. We also used the parameters for random, or directed, dispersal according to whichever one gave the lowest AIC for each species.

\section{Results}

\subsection{Colonization rate}

When drivers were compared individually, dispersal was the best single driver explaining most species local colonization, with a probability close to 1 . This occurred when all species were used (Fig 2), and for subsets of the data partitioned by functional type, or by dispersal vector (Figs. 2 and A.1).

When all driver combinations were considered, the saturated model (that contained all three drivers) was the best-fitting model (median $w_{i}=0.85$; Fig. 2), followed by the 'climate plus dispersal' model (median $\left.w_{i}=0.14\right)$. There was, however, some variation among functional groups. Needle-leaved species provided greater support for the saturated model (median $w_{i}=0.99$ ), whereas deciduous broad-leaved trees provided less support for the saturated model $\left(\right.$ median $w_{i}=$ 0.36), with 'climate plus dispersal' as the second-best model for this group (median $w_{i}=0.17$ ).

\subsection{Extinction rate}

When all species were analysed together, climate and dispersal ranked relatively similar as single predictors of local extinctions (the median $w_{i}$ of the dispersal model was 0.22 and the median $w_{i}$ 
of the climate model was 0.12: Fig. 2). Dispersal was more important for extinctions in needleleaved species (median $w_{i}=0.71$ ), and climate was more important for extinctions in deciduous broad-leaved species (median $\left.w_{i}=0.63\right)$.

When all extinction models were compared, the saturated model (with climate, interactions, and dispersal) was best supported (median $w_{i}=0.66$ ). The saturated model was also best-supported for deciduous broad-leaved species (median $w_{i}=0.59$ ), and needle-leaved species (median $w_{i}=0.87$ ).

Colonization and extinction patterns did not differ appreciably between wind- and animaldispersed species (Fig. A.1). Nevertheless, as explained in the methods, we did not constrain the type of dispersal function that would describe either the wind- or the animal-dispersed species. We permitted random dispersal functions for animal-dispersed species and directed-dispersal functions for wind dispersed species if they fit the data more parsimoniously (but see Montoya et al., 2008).

\subsection{Magnitude and direction of effects}

The direction and magnitude of winter precipitation, summer maximum temperature and total basal area, and the magnitude of the closeness and number of occupied plots, varied among species and among functional groups (Fig. 3). Higher winter precipitation reduced both colonization and extinction rates in 5 out of 8 needle-leaved species. In contrast, for deciduous broad-leaved species, higher winter precipitation had a marked positive effect and tended to both increase colonization (12 out of 13 species) and decrease extinction (9 out of 13 species). Higher maximum summer temperatures increased the colonization rate of half of the needle-leaved species and decreased it for the other half, while increasing the extinction rate of 5 out of 8 species in that group. Higher 
temperatures had a negative effect on the colonization of 7 of the 13 deciduous broad-leaved species, but also decreased the extinction rate of 7 out of 13 of these species.

There was pronounced variation among functional groups in the effect of species interactions, as measured by the total basal area of other species in the plot (BA). Greater BA decreased the colonization rate of the 8 needle-leaved species ( $p<0.05$ for 6 species), and increased the extinction rate of 6 of the 8 needle-leaved species ( $p<0.05$ for 5 species). There was some evidence that BA also decreased the colonization rate of deciduous broad-leaved species ( 9 of the 13 species had posterior means below zero), but only one of these effects had a $95 \%$ confidence interval that did not include zero. BA decreased, rather than increased, extinction rate for 7 of the 13 deciduous broad-leaved species.

The parameters associated with dispersal varied considerably among species. With the exception of Juniperus communis and Juniperus phoenicea, the dispersal parameters for needle-leaved species were smaller (= shorter dispersal distances) than for deciduous broad-leaved species. Similarly, with the exception of Juniperus communis, Juniperus phoenicea and Pinus nigra, the dispersal kernels associated with extinction also had shorter tails for needle-leaved species versus broad-leaved species.

\section{Discussion}

We quantified the relative importance of climate, interspecific interactions, and dispersal on plotlevel colonization and extinction rates of 23 dominant tree species across mainland Spain. All three drivers were crucial to understand local colonization and the extinction of most species, but their 
relative importance differed between the two processes, among species from different functional groups, and, in some cases, among species within groups. We also observed differences among species in the direction and magnitude of the influence that each driver had on both the colonization and extinction rates.

Our results suggest that dispersal is a key driver for colonization of most tree species in these forests, which is consistent with other evidence for dispersal effects in this region (e.g. Gómez, 2003; Pons and Pausas, 2007). The critical importance of dispersal on species distributions might be even more evident in mainland Spain (Gómez-Aparicio, 2008; Purves et al., 2007) because rural abandonment and decreasing forest management are allowing tree species to expand beyond their current areas of occupation (García-Valdés et al., 2013). Besides, palynological evidence indicates progressive tree species occupation of suitable climatic regions following the Last Glacial Maximum (LGM; Carrión et al., 2003; Petit et al., 2002), and a number of European studies also suggest that post-glacial dispersal limitations explain the limited occurrence of trees and other taxa at their range limits in northern Europe (Montoya et al., 2007; see also Munguía et al., 2012; Svenning et al., 2008; Svenning and Skov, 2004). Moreover, as in our study, incorporating dispersal variables improved the performance of SDMs for plants in the French Alps (Boulangeat et al., 2012).

Dispersal also plays a role in species extinctions. For Iberian trees, a "rescue effect" (Brown and Kodric-Brown, 1977) produced by seed dispersal may have reduced extinctions of needle-leaved species (Fig. 2). This process becomes important for species that are poor competitors (Holt et al., 2005) but can maintain sink populations through the input of new seeds from other populations 
(Freckleton and Watkinson, 2002). We also found that needle-leaved species showed shorter dispersal kernels, especially noticeable in the colonization process. This could reflect that these species tend to be more spatially aggregated since they are poor competitors and are displaced when other species arrive, or that having close and abundant populations was crucial for the colonization process since a small number of seed would have not succeed in colonizing an already occupied plot.

Climate is broadly correlated with plant species occurrences at the continental scale (Beerling et al., 1995; Hawkins et al., 2003; Pearson et al., 2002; Walther et al., 2005), and energy and water availability are important determinants of species occurrence in Iberian forests (Pigott and Pigott, 1993; Whittaker et al., 2007; Zavala et al., 2000). Our results indicate that climatic factors are an important complement to dispersal for colonizations, and are even more important for extinctions. In our study, deciduous broad-leaved species were especially sensitive to climatic variables (Fig 2), possibly because these species are more dependent on water than needle-leaved species. Moreover, water availability correlates with forest decline and tree mortality in Iberian forests (Carnicer et al., 2011; Sanchez-Salguero et al., 2012), and greater winter precipitation had a patent positive effect on deciduous broad-leaved species. However, no strong different effect of temperature was observed between functional groups. This might be due to the great functional diversity within each group with both needle- and broad-leaved species exhibiting a range variation in climatic tolerance (e.g. Montoya et al., 2009; Sánchez-Gómez et al., 2008a),

In addition to dispersal and environmental factors, species colonization patterns are also influenced by species interactions (Frelich et al., 1993). Competition is recognized as a key driver of tree 
species distributions at local spatial scales (e.g. Pacala et al., 1996), and, in Mediterranean forests, the effects of competition can be modulated by environmental conditions (e.g. Díaz-Sierra et al., 2010; Gómez-Aparicio et al., 2011; Holmgren et al., 1997). High levels of other tree species' basal area have a strong negative effect on colonization and increased extinction of needle-leaved species, but much weaker effects on broad-leaved species. Most Iberian pines species can easily colonize open spaces after disturbances; nevertheless, they tend to be excluded in later stages of succession due to shade intolerance of their saplings (Zavala and Zea, 2004). In fact, needle-leaved species can facilitate the establishment and colonization of broad-leaved species (e.g. Lookingbill and Zavala, 2000) leading to an expansion of their realized niche (e.g. Urbieta et al., 2008).

Abundance, estimated as basal area of other tree species was also an important correlate of species extinctions rates in Iberian trees. More generally, interactions between tree species are an important determinant of species occurrence (Leathwick and Austin, 2001) and can improve the performance of SDMs when they are considered (Boulangeat et al., 2012; Meier et al., 2010; Meineri et al., 2012; Trivino et al., 2011). At local scales, competition is an important driver of secondary succession, with species upper limits along a productivity gradient being controlled by shade tolerance (Pacala et al., 1996; Tilman, 1994). That the effect of basal area is less negative for broadleaved species than for needle-leaved species might represent a greater role of facilitation for broadleaves species, which are typically more shade tolerant (Sánchez-Gómez et al., 2008b). However, the magnitude of the potential facilitative effects within the broad-leaved species was less important than the potential competitive effects experienced by the needle-leaved species. 


\section{CONCLUSIONS}

For Iberian tree species, non-climatic factors are important determinants of stand-level colonization and extinction rates. Although variation in the combination of best-fitting predictor variables is not always easy to interpret, in this study, dispersal and the sum of basal area of other tree species consistently emerged as important predictor variables, and their effects were at least as strong as the climatic variables. Moreover, the three drivers together were consistently better than any partial combination of drivers. In our opinion, this shows that studying the interaction among different factors driving species local colonizations and extinctions is crucial to understand species local dynamics, and ultimately spatial distributions. In this study, the data were collected across a broad spatial extent but with fine resolution. It is not clear yet whether non-climatic factors will be as important in data sets collected at coarser resolutions. However, it seems likely that a mix of factors reflecting climate, species interactions, and dispersal will contribute to patterns of tree colonization and extinction at spatial scales from local to biogeographic.

\section{Acknowledgements}

We thank the Spanish Ministry of Agriculture, Food and the Environment for granting access to forest inventory data. This research is supported by projects VULPINECLIM (CGL2013-44553R) and previously by INTERBOS3-CGL2008-04503-C03-03 (Spanish Ministry of Science and Innovation MCI) and REMEDINAL2 (CAM, S2009/AMB-1783). R.G.V was supported by a F.P.IM.C.I (BES-2007-14404) fellowship. MBA acknowledges the Imperial College London's Grand Challenges in Ecosystems and Environment initiative for support of his research. We thank Paloma Ruiz Benito for critical assistance with SFI database management and Isaac Pozo for help with data handling and computational tools. 


\section{References}

Araújo, M.B., Luoto, M., 2007. The importance of biotic interactions for modelling species distributions under climate change. Global Ecology and Biogeography 16, 743-753.

Araújo, M.B., Pearson, R.G., 2005. Equilibrium of species' distributions with climate. Ecography 28, 693-695.

Araújo, M.B., Peterson, A.T., 2012. Uses and misuses of bioclimatic envelope modeling. Ecology 93, 1527-1539.

Araújo, M.B., Rozenfeld, A., 2014. The geographic scaling of biotic interactions. Ecography 37, 406-415.

Beerling, D.J., Huntley, B., Bailey, J.P., 1995. Climate and the distribution of Fallopia japonica: use of an introduced species to test the predictive capacity of response surfaces. Journal of Vegetation Science 6, 269-282.

Boulangeat, I., Gravel, D., Thuiller, W., 2012. Accounting for dispersal and biotic interactions to disentangle the drivers of species distributions and their abundances. Ecology Letters 15, 584-593.

Brown, J.H., Kodric-Brown, A., 1977. Turnover rates in insular biogeography: effect of immigration on extinction. Ecology 58, 445-449.

Burnham, K.P., Anderson, D.R., 2002. Model selection and multimodel inference: a practical information-theoretic approach. Springer, New York 488 pp.

Carnicer, J., Coll, M., Ninyerola, M., Pons, X., Sánchez, G., Peñuelas, J., 2011. Widespread crown condition decline, food web disruption, and amplified tree mortality with increased climate change-type drought. Proceedings of the National Academy of Sciences of the United States of America 108, 1474-1478.

Carrión, J.S., Sánchez-Gómez, P., Mota, J.F., Yll, R., Chaín, C., 2003. Holocene vegetation dynamics, fire and grazing in the Sierra de Gádor, southern Spain. The Holocene 13, 839849.

Davis, A.J., Jenkinson, L.S., Lawton, J.H., Shorrocks, B., Wood, S., 1998. Making mistakes when predicting shifts in species range in response to global warming. Nature 391, 783786.

Díaz-Sierra, R., Zavala, M.A., Rietkerk, M., 2010. Positive interactions, discontinuous transitions and species coexistence in plant communities. Theoretical Population Biology 77, 131144.

Engler, R., Randin, C.F., Vittoz, P., Czáka, T., Beniston, M., Zimmermann, N.E., Guisan, A., 2009. Predicting future distributions of mountain plants under climate change: does dispersal capacity matter? Ecography 32, 34-45.

Freckleton, R.P., Watkinson, A.R., 2002. Large-scale spatial dynamics of plants: metapopulations, regional ensembles and patchy populations. Journal of Ecology 90, 419434.

Frelich, L.E., Calcote, R.R., Davis, M.B., Pastor, J., 1993. Patch Formation and Maintenance in an Old-Growth Hemlock-Hardwood Forest. Ecology 74, 513-527.

García-Valdés, R., Svenning, J.-C., Zavala, M.A., Purves, D.W., Araújo, M.B., 2015. Evaluating the combined effects of climate and land-use change on tree species distributions. Journal of Applied Ecology, n/a-n/a. 
García-Valdés, R., Zavala, M.A., Araújo, M.B., Purves, D.W., 2013. Chasing a moving target: projecting climate change-induced shifts in non-equilibrial tree species distributions. Journal of Ecology 101, 441-453.

Godsoe, W., Harmon, L.J., 2012. How do species interactions affect species distribution models? Ecography 35, 811-820.

Gómez-Aparicio, L., 2008. Spatial patterns of recruitment in Mediterranean plant species: linking the fate of seeds, seedlings and saplings in heterogeneous landscapes at different scales. Journal of Ecology 96, 1128-1140.

Gómez-Aparicio, L., García-Valdés, R., Ruíz-Benito, P., Zavala, M.A., 2011. Disentangling the relative importance of climate, size and competition on tree growth in Iberian forests: implications for forest management under global change. Global Change Biology 17, 2400-2414.

Gómez, J.M., 2003. Spatial patterns in long-distance dispersal of Quercus ilex acorns by jays in a heterogeneous landscape. Ecography 26, 573-584.

Gonzalo, J., 2008. Diagnosis Fitoclimática de la España Peninsular. Actualización y análisis geoestadístico aplicado. Universidad Politécnica de Madrid, Madrid.

Gotelli, N.J., Anderson, M.J., Arita, H.T., Chao, A., Colwell, R.K., Connolly, S.R., Currie, D.J., Dunn, R.R., Graves, G.R., Green, J.L., Grytnes, J.A., Jiang, Y.H., Jetz, W., Kathleen Lyons, S., McCain, C.M., Magurran, A.E., Rahbek, C., Rangel, T.F., Soberón, J., Webb, C.O., Willig, M.R., 2009. Patterns and causes of species richness: a general simulation model for macroecology. Ecol Lett 12, 873-886.

Green, P.J., 1995. Reversible jump Markov chain Monte Carlo computation and Bayesian model determination. Biometrika 82, 711-732.

Hampe, A., 2004. Bioclimate envelope models: what they detect and what they hide. Global Ecology and Biogeography 13, 469-471.

Hawkins, B.A., Field, R., Cornell, H.V., Currie, D.J., Guegan, J.F., Kaufman, D.M., Kerr, J.T., Mittelbach, G.G., Oberdorff, T., O'Brien, E.M., Porter, E.E., Turner, J.R.G., 2003. Energy, water, and broad-scale geographic patterns of species richness. Ecology 84, 31053117.

Hof, C., Brandle, M., Dehling, D.M., Munguía, M., Brandl, R., Araújo, M.B., Rahbek, C., 2012. Habitat stability affects dispersal and the ability to track climate change. Biol Lett 8, 639643.

Holmgren, M., Scheffer, M., Huston, M.A., 1997. The Interplay of Facilitation and Competition in Plant Communities. Ecology 78, 1966-1975.

Holt, R.D., Keitt, T.H., Lewis, M.A., Maurer, B.A., Taper, M.L., 2005. Theoretical models of species' borders: single species approaches. Oikos 108, 18-27.

Ibáñez, I., Clark, J.S., Dietze, M.C., Feeley, K., Hersh, M., LaDeau, S., McBride, A., Welch, N.E., Wolosin, M.S., 2006. Predicting biodiversity change: Outside the climate envelope, beyond the species-area curve. Ecology 87, 1896-1906.

Iverson, L.R., Prasad, A.M., 1998. Predicting abundance of 80 tree species following climate change in the eastern United States. Ecological Monographs 68, 465-485.

Kissling, W.D., Dormann, C.F., Groeneveld, J., Hickler, T., Kühn, I., McInerny, G.J., Montoya, J.M., Römermann, C., Schiffers, K., Schurr, F.M., Singer, A., Svenning, J.-C., Zimmermann, N.E., O’Hara, R.B., 2012. Towards novel approaches to modelling biotic interactions in multispecies assemblages at large spatial extents. Journal of Biogeography 39, 2163-2178. 
Leathwick, J.R., Austin, M.P., 2001. Competitive interactions between tree species in New Zealand's old-growth indigenous forests. Ecology 82, 2560-2573.

Lookingbill, T.R., Zavala, M.A., 2000. Spatial pattern of Quercus ilex and Quercus pubescens recruitment in Pinus halepensis dominated woodlands. Journal of Vegetation Science 11, 607-612.

Meier, E.S., Kienast, F., Pearman, P.B., Svenning, J.-C., Thuiller, W., Araújo, M.B., Guisan, A., Zimmermann, N.E., 2010. Biotic and abiotic variables show little redundancy in explaining tree species distributions. Ecography 33, 1038-1048.

Meineri, E., Skarpaas, O., Vandvik, V., 2012. Modeling alpine plant distributions at the landscape scale: Do biotic interactions matter? Ecological Modelling 231, 1-10.

Montoya, D., Purves, D.W., Urbieta, I.R., Zavala, M.A., 2009. Do species distribution models explain spatial structure within tree species ranges? Global Ecology and Biogeography 18, 662-673.

Montoya, D., Rodríguez, M.A., Zavala, M.A., Hawkins, B.A., 2007. Contemporary richness of holarctic trees and the historical pattern of glacial retreat. Ecography 30, 173-182.

Montoya, D., Zavala, M.A., Rodríguez, M.A., Purves, D.W., 2008. Animal versus wind dispersal and the robustness of tree species to deforestation. Science 320, 1502-1504.

Munguía, M., Rahbek, C., Rangel, T.F., Diniz-Filho, J.A., Araújo, M.B., 2012. Equilibrium of global amphibian species distributions with climate. Plos One 7, e34420.

Pacala, S.W., Canham, C.D., Saponara, J., Silander, J.A., Kobe, R.K., Ribbens, E., 1996. Forest models defined by field measurements: Estimation, error analysis and dynamics. Ecological Monographs 66, 1-43.

Pearson, R.G., Dawson, T.P., 2003. Predicting the impacts of climate change on the distribution of species: are bioclimate envelope models useful? Global Ecology and Biogeography 12, 361-371.

Pearson, R.G., Dawson, T.P., Berry, P.M., Harrison, P.A., 2002. SPECIES: A Spatial Evaluation of Climate Impact on the Envelope of Species. Ecological Modelling 154, 289-300.

Peterson, A.T., Soberón, J., Sánchez-Cordero, V., 1999. Conservatism of ecological niches in evolutionary time. Science 285, 1265-1267.

Petit, R.J., Brewer, S., Bordacs, S., Burg, K., Cheddadi, R., Coart, E., Cottrell, J., Csaikl, U.M., van Dam, B., Deans, J.D., Espinel, S., Fineschi, S., Finkeldey, R., Glaz, I., Goicoechea, P.G., Jensen, J.S., Konig, A.O., Lowe, A.J., Madsen, S.F., Matyas, G., Munro, R.C., Popescu, F., Slade, D., Tabbener, H., de Vries, S.G.M., Ziegenhagen, B., de Beaulieu, J.L., Kremer, A., 2002. Identification of refugia and post-glacial colonisation routes of European white oaks based on chloroplast DNA and fossil pollen evidence. Forest Ecology and Management 156, 49-74.

Pigott, C.D., Pigott, S., 1993. Water as a determinant of the distribution of trees at the boundary of the Mediterranean zone. Journal of Ecology 81, 557-566.

Pons, J., Pausas, J., 2007. Acorn dispersal estimated by radio-tracking. Oecologia 153, 903-911.

Pugnaire, F.I., Haase, P., Puigdefábregas, J., 1996. Facilitation between Higher Plant Species in a Semiarid Environment. Ecology 77, 1420-1426.

Pulliam, H.R., 2000. On the relationship between niche and distribution. Ecology Letters 3, 349361.

Purves, D.W., Zavala, M.A., Ogle, K., Prieto, F., Benayas, J.M.R., 2007. Environmental heterogeneity, bird-mediated directed dispersal, and oak woodland dynamics in Mediterranean Spain. Ecological Monographs 77, 77-97. 
R Core Team, 2014. R: A language and environment for statistical computing. R Foundation for Statistical Computing, Vienna, Austria.

Sánchez-Gómez, D., Zavala, M.A., Valladares, F., 2008a. Functional traits and plasticity linked to seedlings' performance under shade and drought in Mediterranean woody species. Annals of Forest Science 65.

Sánchez-Gómez, D., Zavala, M.A., Van Schalkwijk, D.B., Urbieta, I.R., Valladares, F., 2008b. Rank reversals in tree growth along tree size, competition and climatic gradients for four forest canopy dominant species in Central Spain. Annals of Forest Science 65.

Sanchez-Salguero, R., Navarro-Cerrillo, R.M., Swetnam, T.W., Zavala, M.A., 2012. Is drought the main decline factor at the rear edge of Europe? The case of southern Iberian pine plantations. Forest Ecology and Management 271, 158-169.

Skov, F., Svenning, C., 2004. Potential impact of climatic change on the distribution of forest herbs in Europe (vol 27, pg 366, 2004). Ecography 27, 827-828.

Svenning, J.-C., Normand, S., Skov, F., 2008. Postglacial dispersal limitation of widespread forest plant species in nemoral Europe. Ecography 31, 316-326.

Svenning, J.-C., Sandel, B., 2013. Disequilibrium vegetation dynamics under future climate change. American Journal of Botany 100, 1266-1286.

Svenning, J.-C., Skov, F., 2004. Limited filling of the potential range in European tree species. Ecology Letters 7, 565-573.

Tilman, D., 1994. Competition and biodiversity in spatially structured habitats. Ecology 75, 2-16.

Trivino, M., Thuiller, W., Cabeza, M., Hickler, T., Araújo, M.B., 2011. The contribution of vegetation and landscape configuration for predicting environmental change impacts on Iberian birds. Plos One 6, e29373.

Urbieta, I.R., Pérez-Ramos, I.M., Zavala, M.A., Marañón, T., Kobe, R.K., 2008. Soil water content and emergence time control seedling establishment in three co-occurring Mediterranean oak species. Canadian Journal of Forest Research-Revue Canadienne De Recherche Forestiere 38, 2382-2393.

van Mantgem, P.J., Stephenson, N.L., Byrne, J.C., Daniels, L.D., Franklin, J.F., Fule, P.Z., Harmon, M.E., Larson, A.J., Smith, J.M., Taylor, A.H., Veblen, T.T., 2009. Widespread increase of tree mortality rates in the western United States. Science 323, 521-524.

Villaescusa, R., Diaz, R. (eds.) 1998. Segundo Inventario Forestal Nacional (1986-1996). Ministerio de Medio Ambiente, ICONA, Madrid, España 337 pp.

Villanueva, J.A. (ed.) 2004. Tercer Inventario Forestal Nacional (1997-2007). Ministerio de Medio Ambiente, Madrid, España.

Walther, G.-R., Berger, S., Sykes, M.T., 2005. An ecological 'footprint' of climate change. Proceedings of the Royal Society B: Biological Sciences 272, 1427-1432.

Whittaker, R.J., Nogués-Bravo, D., Araújo, M.B., 2007. Geographical gradients of species richness: a test of the water-energy conjecture of Hawkins et al. (2003) using European data for five taxa. Global Ecology and Biogeography 16, 76-89.

Wisz, M.S., Pottier, J., Kissling, W.D., Pellissier, L., Lenoir, J., Damgaard, C.F., Dormann, C.F., Forchhammer, M.C., Grytnes, J.-A., Guisan, A., Heikkinen, R.K., Høye, T.T., Kühn, I., Luoto, M., Maiorano, L., Nilsson, M.-C., Normand, S., Öckinger, E., Schmidt, N.M., Termansen, M., Timmermann, A., Wardle, D.A., Aastrup, P., Svenning, J.-C., 2013. The role of biotic interactions in shaping distributions and realised assemblages of species: implications for species distribution modelling. Biological Reviews 88, 15-30. 
Woodward, F.I., Fogg, G.E., Heber, U., 1990. The Impact of Low Temperatures in Controlling the Geographical Distribution of Plants [and Discussion]. Philosophical Transactions of the Royal Society B: Biological Sciences 326, 585-593.

Zavala, M.A., Espelta, J.M., Retana, J., 2000. Constraints and trade-offs in Mediterranean plant communities: The case of holm oak-Aleppo pine forests. Botanical Review 66, 119-149.

Zavala, M.A., Zea, E., 2004. Mechanisms maintaining biodiversity in Mediterranean pine-oak forests: insights from a spatial simulation model, 2nd International Conference on Mediterranean Pines. Kluwer Academic Publ, Chania, Greece, pp. 197-207. 


\section{Figures}

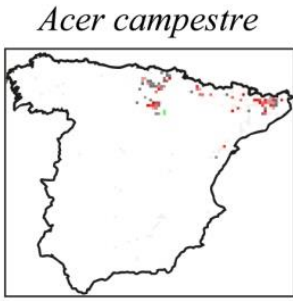

Fraxinus angustifolia

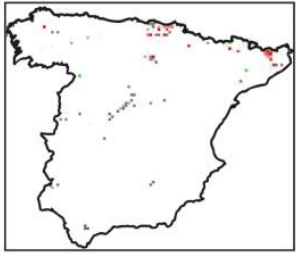

Pinus halepensis

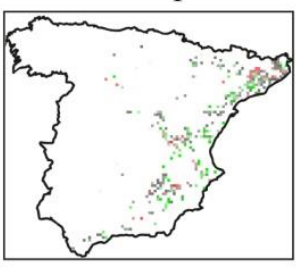

Pinus sylvestris

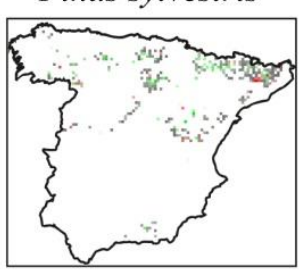

Quercus ilex

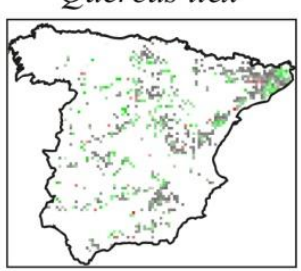

Quercus suber

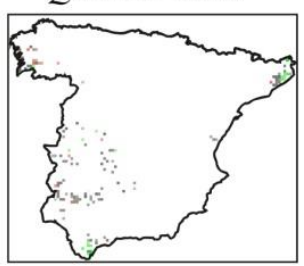

Alnus glutinosa

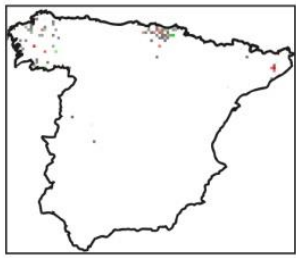

Juniperus communis

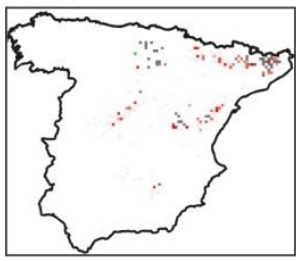

Pinus nigra

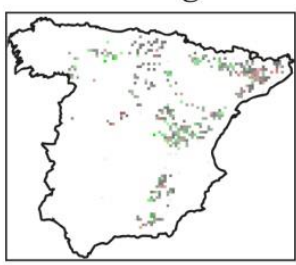

\section{Prunus spp.}

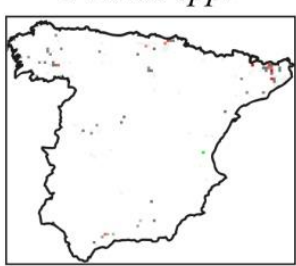

Quercus petraea

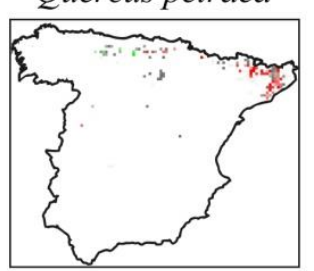

Salix spp.

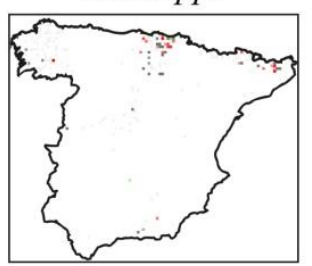

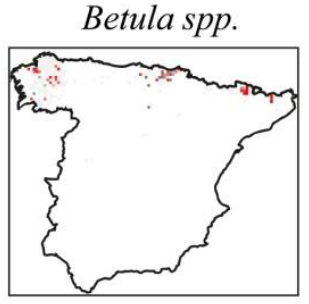

Juniperus phoenicea

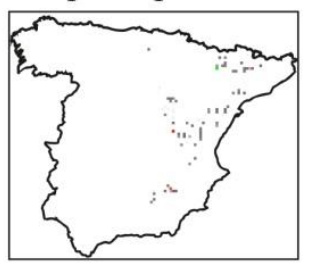

Pinus pinaster

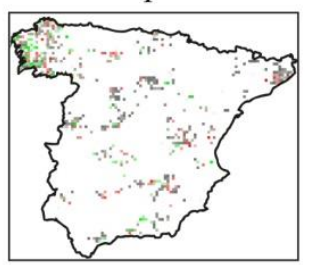

Quercus canariensis

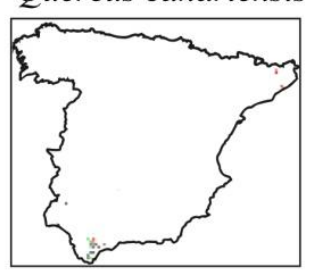

Quercus pyrenaica

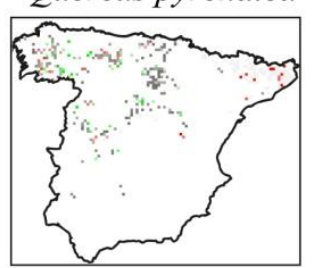

Tilia spp.

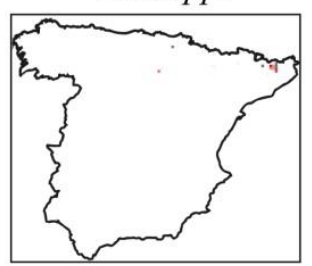

Corylus avellana
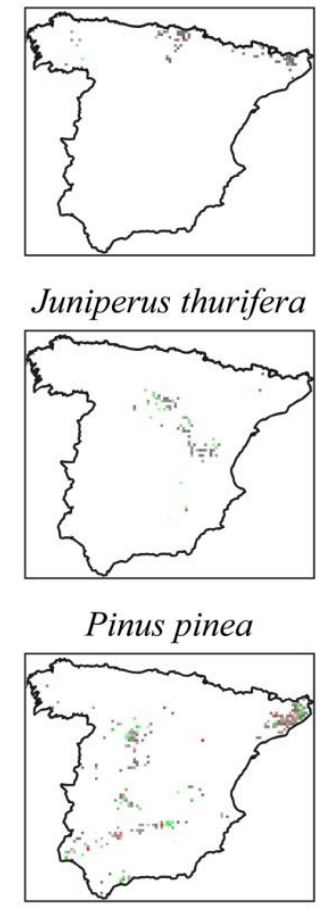

Quercus faginea

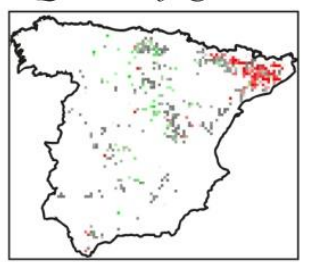

Quercus robur
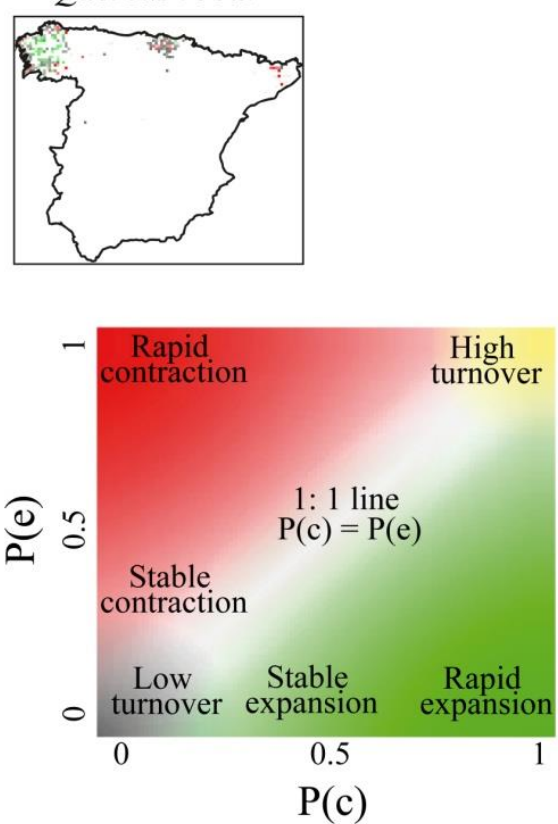
Figure 1: Tree species expansion and contraction areas. For each species, we show the fraction of survey plots that were colonized - $\mathrm{P}(\mathrm{c})$ - and that went extinct - $\mathrm{P}(\mathrm{e})$ - in each $10 \times 10 \mathrm{~km}$ grid cell across mainland Spain. Colour coding indicates different dynamics, based on combinations of extinction and colonization rates. Green $=$ rapid expansion, red $=$ rapid contraction, yellow $=$ high turnover, grey $=$ low turnover. 


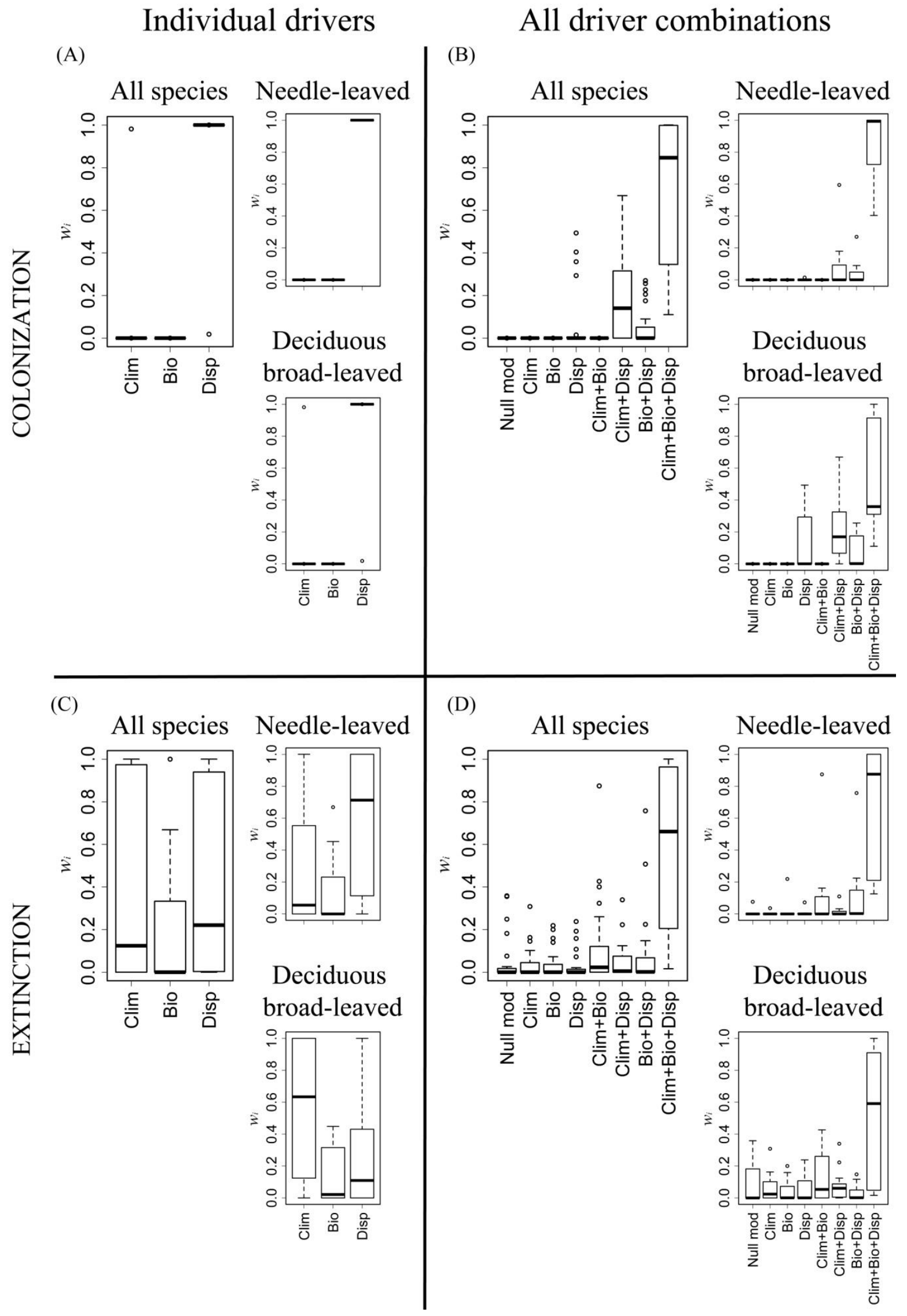


Figure 2: Boxplots of the probability for each combination of drivers to be the best one describing colonizations and extinctions. Fist, only one-driver models were compared (panels A and C), and later all models were compared (panels B and D). On the left part of each panel, all species were included, and in the right part of each panel species were assigned to functional groups (all species $\mathrm{N}=23$, needle-leaved species $\mathrm{N}=8$ and deciduous broad-leaved species $\mathrm{N}=13$ ). 
Local colonization
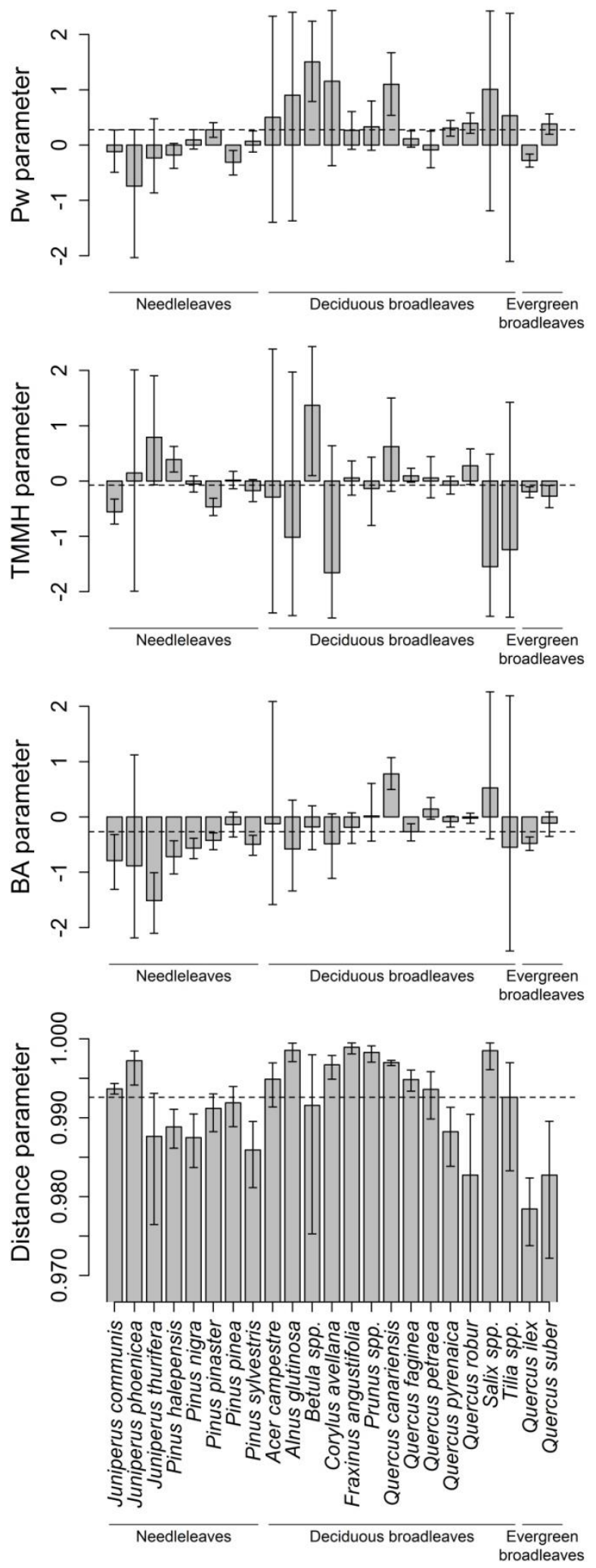

Local extinction
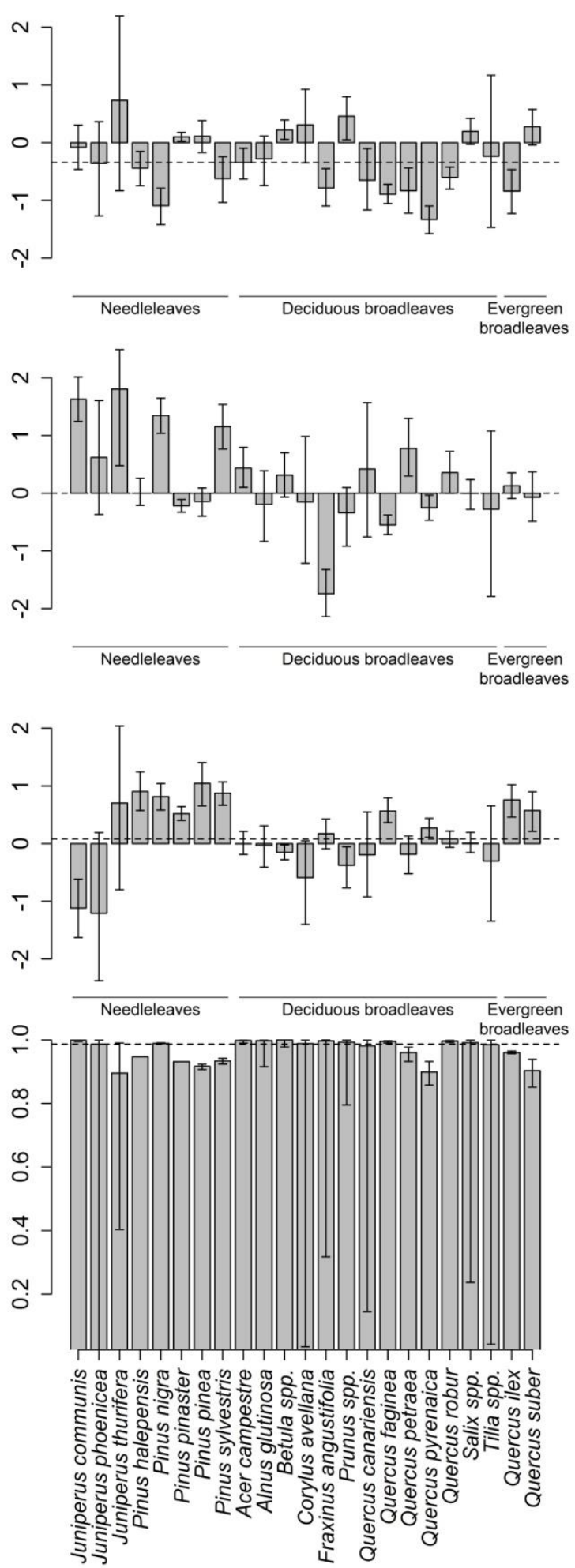

Needleleaves Deciduous broadleaves $\begin{gathered}\text { Evergreen } \\ \text { broadleaves }\end{gathered}$ 
Figure 3: Parameters and 95\% credible intervals for each species using the best saturated model that included the target variable using only one parameter. The target variables were: winter precipitation $(\mathrm{Pw})$, maximum temperature of the hottest month $(\mathrm{TMMH})$, basal area $(\mathrm{BA})$, and a distance combined parameter. Positive values imply that colonization (left panels) or extinction (right panels) are increased when there is a higher precipitation, temperature, or density of competitors in the plot respectively (six top panels). In the two bottom panels, we combined the two parameters that were used for the dispersal kernel, $\sigma$ and $\lambda$, as: $\left(\exp \left[-\left(\frac{1}{\sigma}\right)^{2}\right]\right)^{\lambda}$. Lower values imply that dispersal from one plot to another declines more quickly as a function of the distance between the plots. Dashed lines represent the species median values. 